\title{
LA VIDA ES MOVIMIENTO \\ COMENTARIO A "EL ENIGMA DE LA ANGUSTIA" de JUAN JOSÉ MARTÍNEZ IBÁÑEZ ${ }^{1}$
}

\author{
Realizada por ROSA VELASCO FRAILE ${ }^{3}$
}

El enigma de la angustia sitúa al lector frente a una fresca e innovadora forma de definir la angustia y también nos sitúa frente a una manera de definir el objetivo de nuestro trabajo como psicoterapeutas psicoanalíticos.

¿Qué es la angustia?

¿El miedo, y la angustia, son la misma cosa?

¿La angustia es un síntoma que siempre está presente en un estado depresivo?

¿Es un estado de ánimo?

¿Es un dolor mental o un dolor corporal?

¿La angustia es una emoción?

¿Angustia y ansiedad son la misma cosa?

¿Los seres humanos se ocupan de la angustia?

¿De la angustia se ocupan los psicoanalistas?

¿Se han ocupado de la angustia los artistas?

¿Freud se ocupó de la angustia?

¿El psicoanálisis contemporáneo relacional se ocupa de la angustia?

Estas son algunas de las cuestiones que están desarrolladas en esta obra, la número 17 de la colección pensamiento relacional. El primer libro de Juan José en esta colección fue Las

\footnotetext{
${ }^{1}$ Realizado en la Sociedad Española de Psicoanálisis. Barcelona, 2 de Febrero de 2018

${ }^{2}$ Médico Psicoanalista. Miembro de la SEP y Presidenta de IARPP-E. Directora del Seminario de la SEP "Patrón relacional". Supervisora en instituciones y en su consulta privada. Publica sus trabajos en diversas revistas especializadas como Rev. Catalana de Psicoanàlisi, CelR, Temas de Psicoanálisis, Aperturas psicoanalíticas, Intercambios, Psychoanalytic Inquiry, e imparte docencia en el ámbito estatal e internacional (México) 3 Velasco Fraile, R. (2018). La vida es movimiento. Comentario a "El enigma de la angustia" de Juan José Martínez Ibáñez. Clínica e Investigación Relacional, 12 (1): 172-176. [ISSN 1988-2939] [Recuperado de www.ceir.info ] DOI: 10.21110/19882939.2018.120113
} 
dos edades de la mente, en el que estaban ya incluidas algunas de las consideraciones que aparecen con más definición en esta nueva obra. El enigma de la angustia contiene un interesante prólogo de Mario Marrone, uno de los principales referentes actuales de la teoría del apego en psicoanálisis, amigo y compañero de Juan José.

Encontramos en este libro varios ejemplos clínicos a través de los cuales podemos adentrarnos en la forma en que, un psicoanalista relacional, trata la angustia en la consulta psicoanalítica. Esta parte me ha interesado especialmente y coincido plenamente con Juan José en que registrar las experiencias emocionales del paciente, en el vínculo analítico, a través del relato, contribuye eficazmente a que el paciente aumente la conexión con su propia subjetividad, con su singular manera de sentir.

La vida es movimiento. Cada una de las etapas de desarrollo de un ser humano se caracteriza por formas sensiblemente diferentes de estar con uno mismo y con el otro. El sufrimiento detiene el desarrollo emocional y tratar la angustia es también volver a poner la vida en movimiento, volver a sentir la libertad de movimiento, para relacionarnos, para crecer y continuar con el desarrollo.

La angustia forma parte de la reacción emocional del crecimiento de un ser humano. Las situaciones nuevas generan un estado anímico de alerta y una consecuente reacción de autodefensa. Sabemos que un miedo extremo puede llevarnos al bloqueo de la acción. Desarrollar capacidad mental para autorregular las reacciones emocionales será imprescindible para seguir avanzando en la vida.

La angustia, un estado mental de disconfort, de malestar, surge ante una experiencia imprevista y ocupa un espacio mental que no quedará libre hasta que no se consiga descifrar el enigma. En muchas ocasiones no es posible, para la propia persona que sufre de angustia, el identificar la experiencia emocional que está conectada con esa desagradable sensación que interfiere el curso de la vida.

Tres ejemplos sobre lo que acabo de comentar están incluidos en este libro:

1-el enojo y fastidio del propio Juan José al descubrir que alguien destrozó los retrovisores de su coche aparcado en la calle.

2-el horror de una mujer que asiste telefónicamente a la muerte repentina de su pareja.

3-la acción espontánea de un hombre en defensa de su propio negocio para contrarrestar la actitud delictiva de un ladrón.

El denominador común de estas tres experiencias es el impacto emocional en cada uno de los protagonistas ante los imprevistos sucesos acaecidos. Si el afecto es el principal 
organizador de la experiencia (Stolorow), la angustia sería pues una expresión emocional, condensada, de una forma precaria y espontánea de organización mental (Siegel). La sensación de disconfort es un denominador común. Juan José Martínez, el autor de este libro, enlaza didácticamente desde un punto de vista del desarrollo evolutivo del ser humano las manifestaciones de angustia, como son las experiencias de separación de la criatura de su principal vínculo de seguridad (Bolvwy). Según las diferentes estructuras de acogida (Coderch) que se hayan tenido en el curso de la vida los acontecimientos serán en mayor o menor medida generadores de angustia.

La principal fuente de transformación de este estado de disconfort es la aceptación de la reacción emocional. Las situaciones nos afectan y no siempre podemos darnos cuenta hasta que punto nos afectan. En cada ocasión en la que un imprevisto nos impacta emocionalmente necesitaremos de una atenta escucha con el objetivo de que la espontánea tendencia a entender y a comprender reaparezca una vez más en nosotros. Los estados de ánimo, como la angustia, son transitorios. Si hemos experimentado con alguien esa acogida a la reacción anímica, con un familiar, con un amigo o con un psicoterapeuta, la angustia disminuye porque de esta forma el espacio mental se libera de ese sufrimiento. Pero los psicoanalistas nos caracterizamos por querer saber un poco más y con el espíritu de investigación como diría Lichtenberg o como propone Juan José, con la disposición a descubrir el enigma, pensamos con el paciente, pensamos en el contexto en el que se producen los hechos, los afectos, porque los afectos son hechos clínicos como dijo Bion, y además pensamos en los contextos de desarrollo, sobretodo si trabajamos analíticamente desde una perspectiva psicoanalítica relacional. Entendiendo la sesión misma, el encuentro analítico, como una nueva experiencia que acoge y busca la transformación de la angustia.

Veamos esto en cada uno de los ejemplos comentados antes:

1-El enfado de Juan José necesita ser acogido en el vínculo de amistad mientras dialoga sobre lo ocurrido con un amigo. Una respuesta muy común es la de "no te irrites, ya pasará...." En realidad el fastidio que nos invade la mente ante una experiencia de ese estilo está lleno de lógica por lo que la experiencia acogedora por excelencia sería la de " te entiendo, da mucha rabia ir a recoger el coche y encontrártelo así, víctima de un acto vandálico". El afecto necesita ser acogido desde la subjetividad misma.

2-El horror de la mujer frente a la pérdida traumática de su pareja necesita ser acogido. El consuelo formará parte del proceso de duelo. El horror tiene que ser legitimado y validado en la experiencia íntima de conexión emocional con alguien, por ejemplo con la o él psicoanalista. 
3-El miedo del hombre que espontáneamente reduce al atracador en su negocio tiene que ser identificado y conectado. La valiente actitud desconectada del afecto miedo le permitió operar igual que trabaja el cirujano en un quirófano. Pero la emergencia de la angustia nos muestra que el miedo tiene que ser identificado y conectado. Ese es el trabajo que realizamos a diario con pacientes que sufren de angustia: Identificar y conectar los afectos. Además, y desde la actitud de entender y de comprender de manera singular con cada uno de nuestros pacientes, tratamos de saber con ellos porqué ahora en el presente su reacción emocional es la que es. Durante el proceso analítico descubriremos juntos "el enigma de la angustia" como le gusta nombrar a este proceso a Juan José, y que és el título de este libro.

Imaginemos cada una de estas reacciones humanas con un denominador común, la vulnerabilidad sentida frente a las situaciones que no deseamos que pasen, imaginemos que esas reacciones emocionales son seguidas de una identificación de los afectos como pueden ser el miedo y la rabia y imaginemos también que podemos hacer una conexión de la adultez actual con el pasado de las experiencias de la infancia. De esta forma, con estos supuestos "El estado de angustia" probablemente sería transitorio y progresivamente la persona se recuperaría del caos o de la rigidez experimentada con un sentimiento de integración mayor (Siegel). La mente nos protege si existe un desarrollo de las capacidades de regulación afectiva. Y en la sociedad de hoy este potencial de desarrollo se tiene mucho más en cuenta que durante las generaciones pasadas (Riera, R.) La evolución humana consiste en esto.

Juan José prefiere pensar que en la infancia no se acostumbra a denominar angustia a los estados de ánimo de miedo y ansiedad y por ello en la etapa adulta el individuo no sabe como autorregular ese estado anímico. Esta es una fórmula para acoger el afecto y validarlo clínicamente muy efectiva. Yo prefiero pensar que las emociones primarias como el miedo o la rabia no pudieron ser identificadas, acogidas y conectadas durante el proceso de desarrollo de la persona por déficits de responsividad en los vínculos principales como recientemente expresaba en el artículo La Interacción en análisis (Velasco). El equilibrio adaptativo alcanzado para sobrevivir en el propio y particular contexto relacional no facilitó, desafortunadamente, el desarrollo de formas más capaces de acoger las expresiones genuinas de afecto. El arte nos ayuda a cambiar equilibrios caducos en el presente, un ejemplo de ello lo detalla espléndidamente Juan José en la traducción de la canción "Help" de los Beatles, para muchos de nosotros, el grupo musical principal de nuestras adolescencias.

¡Ayuda! necesito a alguien, 
Ahora encuentro que mi mente ha cambiado,

He abierto las puertas de par en par,

Ayúdame si puedes,

Los versos de John Lennon nos sitúan frente a un momento vital de cambio. En esa circunstancia de vulnerabilidad, propia del género humano, se busca ayuda, se busca relación, se busca acogida..., para que la vida, que es movimiento, continúe y SI, entonces hemos cambiado. Estamos continuamente cambiando porque la vida es movimiento (Velasco), pero los humanos somos así de particulares, necesitamos del semejante para seguir vivos y esa necesidad nos hace fuertes y nos constituye en la especie que más ha evolucionado. Paradójicamente, en los seres humanos, la aceptación de la propia fragilidad nos hace consistentes y fuertes.

Te agradezco Juan José todas las reflexiones que surgieron en mí tras la lectura de tu libro, libro que recomiendo a cualquier interesado en la angustia y en el movimiento de la vida.

Ahora proyectaré en la pantalla los versos de John Lennon con su música para contribuir a introducirnos en la propuesta del autor de El enigma de la angustia.

\section{Referencias:}

Coderch de Sans, Joan. (2013). Prólogo al libro de Raimundo Guerra. El clavo ardiendo. Ed. Octaedro. Barcelona

Martinez Ibañez, Juan José (2017). El enigma de la angustia. Ed. Ágora relacional. Madrid

Martinez lbañez, Juan José (2013). Las dos edades de la mente. Ed. Ágora relacional. Madrid

Riera Alibés, Ramon (2010). La Conexión emocional. Ed. Octaedro. Barcelona

Velasco Fraile, Rosa (2018). "La interacció en anàlisi" Rev. Catalana de Psicoanàlisi (versión actualizada, una primera versión en CeIR) Barcelona

Velasco Fraile, Rosa (2014). Prólogo al libro de Joan Coderch. Avances en Psicoanálisis Relacional. Ed. Ágora relacional. Madrid

Velasco Fraile, Rosa (2012). "El trauma a l'etapa de les vergonyes". En Rev. Catalana de Psicoanálisi. Ed. Instituto de Psicoanálisis de Barcelona (IPB) 